\title{
Evaluation of Knowledge and practices of physical therapist about discharge summary documentation in cardiac surgery patients
}

\author{
Lajwanti L. Lalwani ${ }^{1}$, Prakash Mohite ${ }^{2}$, Vanita Lalwani ${ }^{3}$, Quazi Syed Zahiruddin ${ }^{4}$, \\ Abhay Gaidhane ${ }^{5}$
}

\begin{abstract}
${ }^{1}$ Assistant Professor, Ravi Nair Physiotherapy College, Datta Meghe Institute of Medical Sciences, Wardha. ${ }^{2}$ Professor, Department of Forensic Medicine, J.N. Medical College, Datta Meghe Institute of Medical Sciences, Wardha.

${ }^{3}$ Lecturer, Shantaram Potdukhe Law College, Chandrapur.

${ }^{4}$ Professor, Department of Community Medicine, J.N. Medical College, Datta Meghe Institute of Medical Sciences, Wardha.

${ }^{5}$ Professor, Department of Community Medicine, J.N. Medical College and Director, School of Epidemiology \& Public Health, Datta Meghe Institute of Medical Sciences, Wardha.

Corresponding Author: Abhay Gaidhane.

E-mail: abhaygaidhane@gmail.com
\end{abstract}

\begin{abstract}
Background: Documentation is very essential in physical therapy department Discharge Summary after cardiac surgery summarizes about progression toward goals and treatment planned at the time of conclusion of treatment in the physical therapy department.so study was planned with the aim to assess the Knowledge and practice of physical therapist about discharge summary documentation in Cardiac surgery patients.

Methodology: A self-administered structured questionnaire was developed and validated The knowledge questionnaire were designed in such a way that each question had 5 choices i.e strongly agree, agree, neutral , disagree, strongly disagree and practice of physical therapist was evaluated as per checklist and files with discharge card was compared and checked.

Results: Strong consensus is observed for all the knowledge questions and practical Checklist analysis shows that mostly low level exercise test and copy of discharge summary in patients file with physical therapy perspective was present in less frequency.

Conclusions: Maximum physical therapist had sufficient knowledge about discharge summary documentation in cardiac surgery patients but practices related to discharge summary documentation were having many shortcomings which need to be improved for the betterment of patient care.
\end{abstract}

Keywords: physical therapy, discharge summary, cardiac surgery, documentation.

\section{INTRODUCTION}

Physical therapy approach is a multidisciplinary care and approach is patient centered and they are a part of multidisciplinary health care team [1]. Physical therapist plays a vital role by optimizing the health of patients and decrease the cardiovascular morbidity , mortality in cardiac unit in various cardiac conditions such as coronary vascular disease, myocardial infraction, pre and post coronary artery bypass graft (CABG) surgery, percutaneous coronary intervention (PCI), congenital heart disease patients and heart transplant or heart valve surgery patients [2]. 
Documentation is essential in Physical therapy practices for holistic patient care to facilitates effective communication between all the health care team members and between rehabilitation team members [1]. Documentation is important for the reimbursement of various services. Documentation writing is a continuous process starts at the time of admission, and is continuously done at periodic intervals during the course of rehabilitation and at the time of discharge [2].

Documentation is very important aspect of ethics as it deals with patient autonomy and his or her consent for the treatment as well all the important aspects about its treatment plan. According to American Physical Therapy Association, there are 4 principle elements of documentation in patient care: 1) Initial examination/evaluation, 2) visit/encounter, 3) re-examination and 4) discharge or discontinuation summary [3].

Discharge Summary summarizes about progression toward goals and treatment planned at the time of conclusion of treatment in the physical therapy department [3]. Discharge planning is a complex process, and requires inputs and contribution of various health care disciplines for the effective discharge planning, which includes formal discharge planning coordinators, nurses, social workers, physical therapists, occupational therapists, and physicians [4].

A study done by Karen Theobald in 2004 on "Coronary artery bypass graft surgery: discharge planning for successful recovery" suggested that there is a need to improve discharge preparation to increase Quality of life of CABG patients [5].

Discharge summary with respect to physical therapy perception is very essential to cope up with day to day issues and activities and to increase the relevance of this document for increasing the Quality of life of cardiac patients. The aim this study was to assess the Knowledge and practice of physical therapist about discharge summary documentation in Cardiac surgery patients in term of physical therapist perception.

\section{METHODOLOGY}

The present cross-sectional study was conducted in the Physiotherapy Schools within Nagpur and Wardha districts in central India. Physical therapist professionals having minimal bachelor's degree working in an academic Institute or corporate hospitals having a cardiac surgery unit in Wardha and Nagpur city and those willing to give written consent were included in the study.

Ethical approval was obtained from the institutional ethical committee and a written informed consent was obtained from all the participants.

The study instrument was a predesigned self-administered questionnaire taking into consideration discharge summary documentation in terms of physical therapist perception in cardiac surgery patients. The tool was validated by experts for construct and was pilot tested.

The study tool was structured in three sections. First part will deal with demographic data of physical therapist second assessed the knowledge and third part contains checklist of practice of physical therapist about discharge card summary documentation in cardiac surgery patients respectively.

Participants who gave consent were personally briefed about the questionnaire and they were requested to return the duly filled forms. The knowledge questionnaire were designed in such a way that each question had 5 choices i.e strongly agree, agree, neutral, disagree, strongly disagree and practice of physical therapist was evaluated as per checklist and files with discharge card was compared and checked.

Total of 116 physical therapists were contacted, however 80 responded and were included in the study. The response rate was $68.9 \%$.

Data was analyzed by the STAT version 14 . The main outcome variables were knowledge and practice of discharge summary documentation and predictor variables were years of experience, qualifications. The test of significance was applied wherever appropriate.

\section{RESULTS}

Table 1 shows that out of all participants $57.5 \%$ are B.P.Th \& $42.5 \%$ are with M.P.Th qualification. $26.2 \%$ of participants were male and $73.7 \%$ were female. Age wise distribution 
showed that maximum participants were in the age of 22-30 years followed by age range of 31-37 yrs. $61.25 \%$ are with clinical and $38.75 \%$ are with teaching designation. Maximum participants in the present study were having 1-4 years of clinical experience i.e. $52.5 \%$. and only $5 \%$ of participants were having 12.1-15 years of experience. $51.2 \%$ of participants were working in corporate hospital and $48.7 \%$ participants were working in institute.

Table 1: Characteristics of the study participants

\begin{tabular}{|l|l|l|}
\hline Participant characteristics & No & Percentage \\
\hline Qualification & & \\
\hline B.P.Th & 46 & 57.5 \\
\hline M.P.Th & 34 & 42.5 \\
\hline Gender & & \\
\hline Male & 21 & 26.2 \\
\hline Female & 59 & 73.7 \\
\hline Age wise distribution (years) & & \\
\hline $22-30$ years & 49 & 61.2 \\
\hline $31-37$ years & 25 & 31.2 \\
\hline $38-44$ years & 5 & 6.2 \\
\hline $45-52$ years & 1 & 1.2 \\
\hline Designation & & \\
\hline Clinical & 49 & 61.25 \\
\hline Teaching & 31 & 38.75 \\
\hline Years of experience & & \\
\hline 1 to 4 years & 42 & 52.5 \\
\hline 4.1 to 8 years & 29 & 36.25 \\
\hline 8.1 to 12 years & 5 & 6.25 \\
\hline 12.1 to 15 years & 4 & 5.0 \\
\hline Working & & \\
\hline Institute & 39 & 48.7 \\
\hline Corporate hospital & 41 & 51.2 \\
\hline & & \\
\hline
\end{tabular}

Table 2: The knowledge questionaries distribution according to likert scale

\begin{tabular}{|l|l|l|l|l|l|l|l|}
\hline $\begin{array}{l}\text { Question } \\
\text { No. }\end{array}$ & $\begin{array}{l}\text { Strongly } \\
\text { disagree }(1)\end{array}$ & $\begin{array}{l}\text { Disagree } \\
(2)\end{array}$ & $\begin{array}{l}\text { Neutral } \\
(3)\end{array}$ & $\begin{array}{l}\text { Agree } \\
(4)\end{array}$ & $\begin{array}{l}\text { Strongly } \\
\text { agree (5) }\end{array}$ & $\begin{array}{l}\text { Weighted } \\
\text { mean }\end{array}$ & $\begin{array}{l}\text { Consensus } \\
\text { score }\end{array}$ \\
\hline 1 & 0 & 3 & 9 & 26 & 42 & 4.34 & $70.84 \%$ \\
\hline 2 & 0 & 0 & 2 & 7 & 71 & 4.86 & $90.20 \%$ \\
\hline 3 & 0 & 0 & 0 & 5 & 75 & 4.93 & $95.46 \%$ \\
\hline 4 & 0 & 7 & 13 & 31 & 29 & 4.02 & $69.19 \%$ \\
\hline 5 & 0 & 0 & 6 & 23 & 51 & 4.35 & $67.16 \%$ \\
\hline 6 & 0 & 0 & 8 & 24 & 48 & 4.50 & $75.88 \%$ \\
\hline 7 & 0 & 0 & 13 & 24 & 43 & 4.38 & $72.69 \%$ \\
\hline
\end{tabular}

Strong consensus is observed for all the questions .this means that all participants (physical therapists) have sufficient knowledge for all the questions about discharge summary documentation in cardiac surgery patients. 
Table 3: Showing the parameters checklist analysis of practices

\begin{tabular}{|l|l|l|}
\hline Sr. no & Question & Present (n=10) \\
\hline 1 & $\begin{array}{l}\text { Documentation of phase 1 of cardiac rehabiliation with } \\
\text { goals achieved and goals not achieved }\end{array}$ & 4 \\
\hline 2 & $\begin{array}{l}\text { Documentation of the enrolment details with follow } \\
\text { updates of all the stable cardiac patient for cardiac } \\
\text { rehabilitation programme in discharge summary. }\end{array}$ & 5 \\
\hline 3 & $\begin{array}{l}\text { Documentation of the vitals, investigations, medications, } \\
\text { precautions to be taken \& patient self-monitoring } \\
\text { technique when to stop exercising and contact physician } \\
\text { if required. }\end{array}$ & 7 \\
\hline 4 & $\begin{array}{l}\text { Documentation of low level exercise tolerance test results } \\
\text { Documentation of home exercise programe at the time of } \\
\text { discharge }\end{array}$ & 7 \\
\hline 5 & $\begin{array}{l}\text { Documentation of Counseling of patient and relative for } \\
\text { joining outpatient cardiac rehabilitation }\end{array}$ & 4 \\
\hline 7 & $\begin{array}{l}\text { Documentation copy of discharge summary in patients } \\
\text { file with physical therapy perspective. }\end{array}$ & 3 \\
\hline
\end{tabular}

Checklist analysis shows that mostly checklist number 4 and 7 were present in less frequency. i.e $\mathrm{n}=3$.followed by checklist number 1 and 4 with frequency i.e. $n=4$.followed by checklist no. 2 with frequency i.e. $n=5$. And checklist no. 3 and 5 were present in most of the discharge cards with frequency i.e. $n=7$.

\section{DISCUSSION}

The present study was designed to evaluate the knowledge and practices of physical therapist about discharge summary documentation in cardiac surgery patients. This present study showed that physical therapists have a positive Consensus score for all the knowledge related questionnaire. Practice related to discharge summary documentation in cardiac surgery patient in terms of physical therapy perspectives showed that out of 7 checklist items/ parameters that documentation of investigation, precautions, enrolment, and home exercise program is done in considerable discharge cards but documentation of low level exercise test, counseling, phase 1 of cardiac rehabilitation and copy of discharge summary in patients file with physical therapy perspective was present in less frequency.To the best of our knowledge this is the first study to be undertaken on knowledge and practices of physical therapy about discharge card summary documentation in cardiac surgery patients.so finding of this study cannot be compared with other researcher. However, we have come across some of the studies.

In a sudy done in 2008, the discharge card included home exercise program instruction, cardiac rehabilitation enrolment instructions \& follow up dates which is in acordance to this present study were maximum discharge card of various hospital had home exercise program and enrolment instructions and Stated that health care cost and readmission to hospital can be decreased if multidisciplinary involvement of dietician, respiratory therapist, physical therapist, social worker, and nurses approach for patient and family education to improve the patient care [6]. Similarly in another study done in 1992 concluded that effectiveness of discharge planning depends on input of various interdisciplinary involvement while planning home care for patients [7].

Another study also supported that practice of documentation were mostly neglected and concluded that many shortcomings are observed in Physiotherapists' documentation. Various Training and education program for physical therapy documentation improvement can be done using nationally accepted recommendation e.g. use of headings and classifications in documentation and emphasize on the importance of documentation in physical therapy. The use of ICF in documentation might provide more detailed information about physical therapy practice and ICF 
is more acceptable classification in physical therapy documentation than any other classification of physical therapy practice [8].

Some studies had shown the following suggestions that can be incorporated to strengthen the documentation. In a review, authors suggest that Electronic Health Records have potential benefits for storage of physical therapist's documents. The authors formed the following recommendations based on the studies' themes: (1) incorporate workflow analysis into system design and implementation; (2) involvement of clinicians or physicians in system development and planning; (3) involving considerable resources for training; (4) testing and planning to check the accuracy of software and hardware working for storage purpose; and (5) adoption of standards for operating data [9]. Some studies had concluded that Reduced the risk of readmission for patients with heart failure is observed when High-quality discharge summaries are provided to the patients [10].

Knowledge related to Discharge summary documentation of cardiac surgery patients had positive Consensus score, as physical therapists are aware about the importance of documentation and it can be made more effective if adequate knowledge of discharge summary is included in curriculum and knowledge about its importance. Practice of Discharge summary documentation of cardiac surgery patients had many shortcomings as discussed with physical therapist who stated that probable reason for this may be inadequate training and improper skills taught in their undergraduate and postgraduate level. Casual approach of physical therapist towards documentation.

Lack of interest amongst physical therapist regarding taking active participation in the documentation of discharge summary in cardiac surgery patients. This can also be due to less experienced participants in the present study. Lack of awareness among physicians in terms of referral and involvement of multidisciplinary approach during discharge summary preparation and its execution to improve the overall patient care and other problems. Maximum Participants (physical therapist) had sufficient knowledge about discharge summary documentation in cardiac surgery patients but practices related to discharge summary documentation were having many shortcomings which need to be improved for the betterment of patient care.

\section{REFERENCES}

1. Olawale OA, Akodu AK, Tabeson EA. Analysis of physiotherapy documentation of patients' records and discharge plans in a tertiary hospital. J Clin Sci 2015;12(2):85-90.

2. O'Sullivan SB, Schmitz TJ, Fulk G. Physical rehabilitation. FA Davis; 2013.

3. American Physical Therapy Association. Guidelines for Physical Therapy Documentation. Available from: http:// www.apta.org. [Last accessed on 2018 Mar 23].

4. Smith BA, Fields CJ, Fernandez N. Physical therapists make accurate and appropriate discharge recommendations for patients who are acutely ill. Phys Therapy 2010;90(5):693-70.

5. Theobald K, McMurray A. Coronary artery bypass graft surgery: discharge planning for successful recovery. J Adv Nurs 2004;47(5):483-91.

6. Paul S. Hospital discharge education for patients with heart failure: what really works and what is the evidence?. Crit Care Nurs 2008;28(2):66-82.

7. Mamon J, Steinwachs DM, Fahey M, Bone LR, Oktay J, Klein L. Impact of hospital discharge planning on meeting patient needs after returning home. Health Serv Res 1992;27(2):155-9.

8. Häyrinen K. Evaluation of physiotherapists' documentation: A retrospective record analysis before the implementation of national recommendations in the EHR system. Electronic Journal of Health Informatics. 2013;8(1):5.

9. Vreeman DJ, Taggard SL, Rhine MD, Worrell TW. Evidence for electronic health record systems in physical therapy. Phys Ther 2006;86(3):434-46.

10. Al-Damluji MS, Dzara K, Hodshon B, Punnanithinont N, Krumholz HM, Chaudhry SI, Horwitz LI. Association of discharge summary quality with readmission risk for patients hospitalized with heart failure exacerbation. Circulation 2015;8(1):109-11.

Acknowledgements - Nil; Source of Funding - Nil; Conflict of Interest - Nil 